\title{
Alister Miskimmon, Ben O'Loughlin and Jinghan Zeng, eds., One Belt, One Road, One Story? Towards an EU-China Strategic Narrative
}

\author{
(Cham: Palgrave Macmillan, 2021), XI + 282p. \$119.99 hardback; \\ $\$ 89.00$ eBook
}

\section{Steven Langendonk ${ }^{1}$}

Accepted: 25 February 2021 / Published online: 10 March 2021

(c) Journal of Chinese Political Science/Association of Chinese Political Studies 2021

This edited volume, which examines contemporary EU-China relations from the perspective of strategic narrative theory (SNT), appears at a time when the COVID19 pandemic and great power competition are stimulating a lively debate on the EU's position in global affairs. The editors -two of whom are co-responsible for formulating SNT- convincingly argue that a tour de force of how power and communication operate in this relationship may provide answers to those looking for new ways to narrate the EU's relations with China. However, its execution raises questions about how SNT can (and should) be employed to generate policy advice.

The book's eight chapters, written by junior and established scholars based in the EU and China, are clustered in two sections which correspond with the prescriptive and analytical aims set out by the editors. Perhaps inevitably given the the nature of edited volumes, engagement with SNT varies considerably between chapters.

The chapters by Miskimmon and O'Loughlin, Liu and Shi and Trigkas in the former section tend towards descriptive accounts with a focus on official statements, elite rhetoric and the development of China's Belt and Road Initiative (BRI) in Europe. As there is no dearth of such accounts in the literature on the EU-China relationship or on the BRI $[1,2]$, their added value is confined to providing policy prescriptions. Miskimmon and O'Loughlin correctly identify the EU's evolution from "value universalism" towards a more pragmatic narrative, and suggest it should proceed with a "building block narrative" in order to overcome its inherent weaknesses and build trust with China via issue-specific cooperation (p. 37). Shi and Trigkas are less convincing in their attempt to "reconstruct perceptions [...] to 'nudge' the EU-China strategic community towards

Steven Langendonk

steven.langendonk@kuleuven.be

1 Leuven International and European Studies, KU Leuven, Parkstraat 45 bus 3609, 3000 Leuven, Belgium 
a positive-sum BRI narrative” (p. 70-71), painting in broad essayistic strokes which often fail to discriminate between explanation and prescription.

While generally sympathetic to book's project, the chapters of the analytical section complicate the delivery of its main argument at an empirical and methodological level. The contributions by Ma, Li, and Feng and Huang each evince a different dimension of a cognitive chasm which separates (elite) interpretation of the relationship and the BRI in Europe and China. Feng and Huang, both affiliated with CICIR, provide a rare account of how Chinese elites' understanding of the EU has evolved since the financial crisis. By showing how the narratives of 'saving Europe from financial disaster' and the BRI were largely ignored in the EU, it points to a dynamic of structurally informed misrecognition which also features prominently in my own fieldwork. Ma likewise posits that the relationship is hindered by the inability of the respective sides to cognitively remove themselves from their "own institution and historical experiences" (p. 111). Finally, Li's analysis of German, British and French media points to deep-seated and stable anxieties about China's growing role in European affairs (see also [3]).

The friction between the two sections at the empirical level draws out the problematic tendency to apply SNT at the level of state or policy rhetoric, and avoid comparatively messy but equally relevant sites of narrative reception [5]. Given the prescriptive aim of the book, doubt is cast on SNT's utility for generating practicable and ethically sound policy advice.

Despite not featuring prominently in the book's main argument, the remaining contributions by Keuleers and Van Noort illustrate the continued promise of SNT as a conceptual site for inter-methodological dialogue [4]. Van Noort should be commended for bringing SNT into dialogue with Steele's reading of ontological security, and the development of a visual analysis of BRI communication. Keuleers' Q methodology-assisted analysis of how South African students interpret Chinese and EU narratives and weave constitutive components into individually differentiated bricolages raises the bar for studies on narrative reception. Considering the editors' own admission that theoretical and methodological obstacles remain for using SNT to "illuminate the substance of EU-China relations" (p. 9), it may be prudent to ground its prescriptive potentiality in the creativity it elicits.

The volume is likely to be of interest to scholars exploring approaches to SNT and may thus stimulate a broader discussion on how it may illuminate, from above as well as below, key relationships in global politics.

\section{References}

1. Bersick, S. 2015. The EU's bilateral relations with China. In The SAGE handbook of European Foreign Policy, ed. K.E. Jørgensen, K. Aarstad, E. Drieskens, K. Laatikainen, and B. Tonra, 615-632. Los Angeles: SAGE Publications.

2. Blanchard, J.F. 2021. Belt and Road Initiative (BRI) blues: Powering BRI research back on track to avoid choppy seas. Journal of Chinese Political Science. 
3. Langendonk, S. 2020. Discourse power as a means to 'Struggle for position': A critical case study of the belt and road narrative's effects on foreign policy formulation in the Netherlands. Journal of Chinese Political Science 25 (2): 241-260.

4. Roselle, L., A. Miskimmon, and B. O'Loughlin. 2014. Strategic narrative: A new means to understand soft power. Media, War \& Conflict 7 (1): 70-84.

5. Wilkinson, C. 2015. The unsaid and unseen: on hearing silences and seeing invisibilities in strategic narratives. Critical Studies on Security 3 (3): 338-340.

Publisher's Note Springer Nature remains neutral with regard to jurisdictional claims in published maps and institutional affiliations.

Steven Langendonk is a doctoral student at Leuven International and European Studies, KU Leuven. His research interests cover the intersection between ideology and foreign policy, Eurocentric biases in international relations scholarship, and diplomatic practice, particularly in the context of China's role in international relations and organizations. He is currently working on a research project on Chinese diplomatic practice in international organisations funded by Research Foundation - Flanders (FWO). 